\title{
ANALISIS NILAI AKHLAK PADA LEGENDA MALIN KUNDANG DALAM PERSPEKTIF ISLAM
}

\author{
Aida Sumardi 1), Ratna Dewi Kartikasari 2), Nindya Ryanti ${ }^{3)}$ \\ Pendidikan Bahasa dan Sastra Indonesia, Fakultas Ilmu Pendidikan, Univeritas \\ Muhammadiyah Jakarta \\ aida.sumardi@umj.ac.id,g4lih_58@yahoo.com
}

\begin{abstract}
ABSTRAK
Penelitian ini membahas tentang nilai akhlak dalam perspektif Islam pada sebuah legenda Malin Kundang. Akhlak merupakan salah satu hal yang sangat penting dalam Islam, jika setiap ajaran Islam selalu berorientasi kepada pembinaan dan pembentukan akhlak yaitu alakhlaq al-karimah. Cerita bisa dihubungkan dengan sejarah karena sejarah memiliki bahan dasar cerita. Jika ditinjau lebih mendalam, banyak pesan dalam cerita rakyat yang dapat diambil, baik dalam pembelajaran secara keseluruhan ataupun ditinjau dari pembelajaran Islam yakni berupa akhlak. Penelitian ini merupakan penelitian kualitatif deskriptif yaitu penelitian yang menggambarkan suatu peristiwa atau kejadian yang terjadi pada saat sekarang. Metode penelitian ini menggunakan fenomenologi karena fenomena yang terjadi pada saat sekarang yaitu jarangnya para orang tua membacakan cerita untuk anak-anaknya. Penelitian yang mengusung cerita Malin Kundang ini akan dijadikan sebuah buku yang dapat dinikmati oleh semua kalangan, tidak hanya kalangan perguruan tinggi melainkan dapat dinikmati juga oleh pihak sekolah ataupun masyarakat umum. Hal ini sesuai dengan isi yang disampaikan di dalam buku bahwa pendidikan akhlak sangat penting diajarkan dan dipraktikkan pada masyarakat terutama pada anak-anak, baik yang sedang mengenyam pendidikan di sekolah ataupun di luar sekolah. Hasil penelitian ini adalah nilai akhlak dalam legenda Malin Kundang yang dilihat berdasarkan tokoh yang terdapat dalam cerita. Tokoh dalam cerita ada empat yaitu, Malin Kundang, Mande Rubiyah (Ibu Malin Kundang), Istri Malin Kundang, dan Nahkoda Kapal. Malin Kundang memiliki akhlak sopan santun, jujur, rendah hati, sombong, dan angkuh. Mande Rubiyah memiliki akhlak penyayang, baik, perhatian, cemas atau khawatir, pemikir, suka sedih, dan pendemdam. Istri Malin Kundang memiliki akhlak angkuh dan pemarah. Nahkoda kapal memiliki akhlak baik hati.
\end{abstract}

Kata Kunci: Nilai, Akhlak, Legenda, Perspektif Islam

\section{ABSTRACT}

This study discusses the moral value in an Islamic perspective on a legend Malin Kundang. Moral is one of the most important this in Islam, if every Islamic teaching is always oriented to the development and formation of morals namely al-aklaq al-karimah. Stories can be linked to history because it has the basic ingredient of history. If reviewed in more depth, many messages in folklore that can be taken, both in learning as whole or in terms of Islamic learning in the form of morals. This reseach is a descriptive qualitative reseach that is research that describes an event or insident that is happening at the present time. This research method uses phenomenology because the phenomenon that occurs at the moment is the rarity of parent reading stories to their children. The reseach that carries the story of Malin Kundang will be made into a book that can be enjoyed be all people, not only the college but can aslo be enjoyed by the school or the general public. This is consistent with the contents conveyed in the book that moral education is very important to be tougth and practiced to the community, especialy to children, both those who are educated at school or outside school. The result of this study is about a moral value in the story of Malin Kundang based on the characters involved in it. There are four characters in the story, they are Malin Kundang, Mande Rubiyah (Mother of Malin 
Kundang), Malin Kundang's wife, and the ship's captain. Mailn Kundang is a character who has a polite, honest, humble, arrogant and swager. While Mande Rubiyah has profile of caring, kind hearted, anxious or worried, thinkers, distressed, and vengeful. Malin Kundang's wife is an arrogant and grumpy character, while the ship's captain is a kind hearted person.

Keywords: Value, Morals, Legends, Islamic Perspective

\section{PENDAHULUAN}

Akhlak yang baik menjadi salah satu tanda kebahagiaan seseorang di dunia dan akhirat. Banyak hadits yang menjelaskan tentang keutamaan akhlak yang baik, juga begitu tingginya kedudukan akhlak. Akhlak yang bermanfaat adalah akhlak yang dilakukan sesorang dengan mengharapkan pahala dari Allah SWT agar mendapatkan surga dan derajat yang tinggi di akhiratnya. Seseorang yang berakhlak baik adalah yang tidak menunggu balasan manusia jika dia berbuat baik padanya. Hal ini sejalan dengan firman Allah dalam Q.S. Al - Baqarah (2): 83

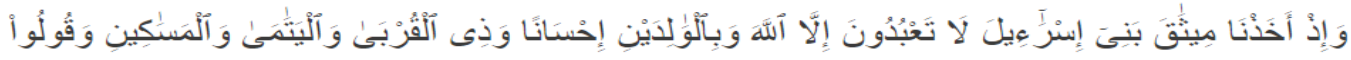

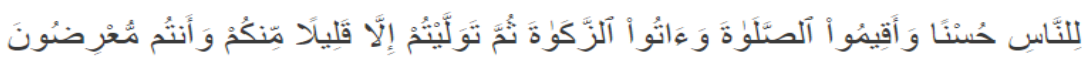

Artinya "Janganlah kamu menyembah selain Allah, dan berbuat baiklah kepada kedua orang tua, kerabat, anak - anak yatim, dan orang - orang miskin. Dan bertutur katalah yang baik dengan manusia".

Akhlak menempati posisi yang sangat penting dalam Islam, jika dilisik setiap ajaran Islam selalu beroreintasi kepada pembinaan dan pembentukan akhlak yaitu al-akhlaq al-karimah. Akhlakiyah (moral) menjadi karakter Islam karena akhlak masuk dalam semua ajarannya, sampai kepada akidah, ibadah, dan muamalah, serta termasuk ke dalam ekonomi dan politik. Umat Islam dalam hidupnya memiliki aturan yaitu Alquran dan Al-Hadist, setiap isi yang terkandung merupakan pedoman hidup dan perbaikan diri untuk mendapatkan ridha Allah SWT. Islam mengajarkan akhlak yang harus dimiliki oleh setiap umat yaitu; 1) akhlak kepada Allah, 2) akhlak kepada Rasulullah, 3) akhlak kepada orang tua, 4) akhlak kepada guru, 5) akhlak kepada manusia, dan 6) akhlak kepada makhluk hidup. Secara terminologi, akhlak merupakan suatu sistem yang melekat pada individu yang menjadikan seseorang menjadi manusia istimewa dari individu lainnya, lalu menjadi sifat pada diri seseorang tersebut. (Nasharudin, 2015: 206).

Perkataan akhlak dalam bahasa Arab disebut "akhlak" jamak dari kata "khuluk" yang menurut Lughat diartikan budi pekerti, perangai, tingkah laku atau tabiat (internal creation) atau kejadian batin (Hamid, 2016: 196). Akhlak pada dasarnya melekat dalam diri seseorang, bersatu dengan perilaku atau perbuatan. Jika perilaku yang melekat itu buruk, maka disebut akhlak yang buruk atau akhlak madzmumah. Sebaliknya, apabila perilaku tersebut baik disebut akhlak mahmudah. Akhlak terbagi menjadi dua: Akhlak Karimah dan Akhlak Madzmumah. Akhlak Karimah seperti beribadah kepada Allah, mencintai-Nya, dan mencintai makhlukNya karena Dia, dan berbuat baik serta menjauhkan diri dari perbuatan-perbuatan 
yang dibenci Allah dan memulai berbuat sholeh dengan niat ikhlas, berbakti kepada orang tua, dan lainnya. Sedangkan Akhlak Madzmumah seperti ujub, sombong, riya', dengki, berbuat kerusakan, bohong, bakhil, malas, dan lain sebagainya. Akhlak mahmudah adalah sebab-sebab kebahagiaan di dunia dan akhirat, yang diridhai Allah, mencintai keluarga dan seluruh manusia, diantara kehidupan mereka kepada seorang Muslim. Sebaliknya akhlak madzmumah adalah asal penderitaan di dunia dan di akhirat.

Hakikat akhlak menurut Al-Ghazali dalam Rizal (2018: 73) seperti kondisi jiwa dan bentuknya yang batin. Sebagaimana sempurnya bentuk lahir secara mutlak yang kemudian menjadi tidak sempurna dengan indahnya keberadaan dua mata saja, tanpa hidung, mulut dan pipi, tetapi kebagusan semuanya harus ada agar kebagusan dhahir menjadi sempurna. Maka, demikian pula dalam urusan batiniah (jiwa), ada empat unsur yang harus baik semua, sehingga kebagusan akhlak menjadi sempurna. Apabila kebagusan empat unsur ini seimbang dan setara serta sesuai maka kebagusan akhlak bisa didapatkan dan niscaya mencapai kemuliaannya. Diantara empat unsur tersebut adalah: kekuatan ilmu, kekuatan emosi, kekuatan syahwat, dan kekuatan adil diantara tiga kekuatan tersebut.

Isi karya sastra dalam pengertian karya tulis ini dapat bermacam-macam, dari karya-karya tulis yang berisi hikayat sampai pada karya tulis yang berisi aturan adat istiadat, tata politik, ajaran agama, ramuan obat-obatan, dan sebagainya (Faruk, 2014: 160). Menurut Nurgiyantoro (2002: 321) karya sastra mengandung penerapan moral dalam sikap dan tingkah laku para tokoh sesuai dengan pandangannya tentang moral. Melalui cerita, sikap, dan tingkah laku tokoh-tokoh itulah pembaca diharapkan dapat mengambil hikmah. Cerita bisa sangat menggugah dan melibatkan berbagai emosi, memengaruhi perilaku dan menentukan pengambilan keputusan seseorang manakala disampaikan secara efektif. Oleh sebab itu cerita bisa digunakan sebagai salah satu metode sosialisasi karakter kepada anak sejak dini dengan menggali kekuatannya. Kekuatan cerita dapat tergali melalui serangkaian kegiatan yang mengarahkan anak untuk melakukan perilaku berkarakter dan menanamkan konsep diri positif (Sunarti, 2005: 9).

Cerita rakyat sebagai salah satu bentuk dari sastra daerah, pasti memiliki ciri. Menurut Endraswara dalam Wahyudin (2016: 3) ciri dari sastra lisan sebagai berikut: (1) cerita adalah milik bersama yaitu masyarakat, (2) ditururunkan dari satu generasi kepada generasi lain melalui penuturan, (3) berfungsi dalam kehidupan serta kepercayaan masyarakat, (4) bisa diwujudkan dalam berbagai bentuk tingkah laku, (5) diciptakan dalam variasi banyak sepanjang masa, (6) bersifat anonim, (7) mengandalkan formula, kisah, simbol, gaya bahasa, dan berbagai gejala kebahasaan lain dalam penampilan atau penceritaannya atau komposisi.

Sedangkan menurut Bascom dalam Wahyudin (2016: 4) sastra lisan memiliki empat fungsi yaitu; (1) sebagi sebuah bentuk hiburan, (2) sebagai pengesahan pranata-pranata dan lembaga-lembaga kebudayaan, (3) sebagai alat pendidikan 
anak, (4) sebagai alat pemaksa dan pengawas agar norma-norma masyarakat akan selalu dipatuhi anggota kolektifnya. Sehingga dapat disimpulkan fungsi cerita rakyat adalah sebagai pelestarian budaya lokal, pembelajaran, hiburan dan religiulitas. Dapat dikatakan fungsi cerita rakyat sangat mendalam bagi setiap sisi, sehingga erat sekali dengan pendidikan upaya wahana pembentukan karakter.

Pulau Sumatra terdiri atas beberapa daerah yaitu Lampung, Sumatra Selatan, Bengkulu, Jambi, Riau, Sumatra Barat, Sumatera Utara, dan Aceh. Kemudian akan dipilih provinsi yang menggambarkan ciri khas dari pulau Sumatra. Daerah yang menjadi ciri khas dari pulau Sumatra, berikut dasar pemilihan cerita yang dimodifikasi (Endraswarta, 2013: 160) yaitu: 1) ceritanya menggambarkan ciri khas pulau Sumatra yaitu melayu, 2) cerita yaitu bagian dari wujud kebudayaan sebagai suatu yang utuh aktivitas serta berpola dari manusia dapat berupa kekhasan kehidupan sehari-hari, dan 3) memiliki nilai etika, pendidikan, folosofis, dan kesejarahan.

Kisah dari Sumatra Barat yang paling banyak dikenal yaitu kisah Malin Kundang. Ceritanya mengenai sebuah keluarga yang terdiri atas ibu dan anak yang miskin dan tinggal di sebuah kam-pung. Untuk memperbaiki kehidupan mereka, si anak yang bernama Malin Kundang pergi merantau. Di rantau, dia sukses dan menikahi seorang gadis. Suatu ketika dia kembali ke kampung halamannya. Sang ibu yang mengetahui hal tersebut, langsung menemuinya. Akan tetapi, Malin Kundang merasa malu melihat kondisi ibunya. Dia menolak mengakui ibunya itu di hadapan istrinya. Akibatnya, sang ibu merasa sedih dan juga marah. Dia berdoa kepada Tuhan supaya anaknya itu diberi ganjaran. Angin kencang dan badai turun dan memorak-porandakan kapal dan segala yang ada di dalamnya. Malin Kundang menyesal, tetapi sudah terlambat. Dia menjadi batu bersama harta bendanya. Sekarang, batu yang dianggap jelmaan Malin Kundang itu berada di Pantai Airmanis, Padang, Sumatra Barat.

Cerita rakyat mengandung banyak falsafah hidup yang dapat dipelajari dalam cerita rakyat. Sejalan dengan hal tersebut cerita rakyat menjadi hal yang menarik untuk diteliti guna mengetahui pesan moral yang terkandung. Selama ini asumsi masyarakat tentang cerita rakyat Malin Kundang adalah anak yang durhaka. Cerita rakyat yang populer dari Sumatra Barat yaitu Malin Kundang, menjadi objek utama dalam penelitian ini untuk mengetahui pesan moral ditinjau dari akhlak dalam Islam.

Dalam legenda Malin Kundang juga terdapat nilai akhlak yang dapat dipedomani dalam kehidupan sehar-hari. Legenda Malin Kundang juga mengajarkan bermacam-macam karakter atau sifat baik dan buruk yang dapat dijadikan pelajaran. Nilai akhlak dalam legenda Malin Kundang berisi pendidikan karakter yang dapat dijadikan contoh dalam dunia pendidikan. Menurut Subaiti, (1995: 25) pendidikan dalam hal ini mencoba untuk mematangkan diri seorang manusia. Memupuk kepribadian seorang manusia menjadi berakhlak dan mulia. Tafsir (1994: 26-27) menyatakan pendidikan merupakan pengembangan pribadi dalam seluruh 
aspek yaitu pendidikan oleh diri sendiri atau lingkungannya dan mencakup akal, jasmani, serta hati. Sejalan dengan hal itu, akhlak merupakan kelakuan, tingkah laku, atau kebiasaan. Akhlak dalam Islam diartikan sebagai perangai atau tingkah laku yang ada dalam diri seseorang yang telah melekat secara terus menerus.

Penelitian ini membahas tentang nilai akhlak dalam perspektif Islam pada sebuah legenda Malin Kundang. Akhlak merupakan salah satu hal yang sangat penting dalam Islam, jika setiap ajaran Islam selalu berorientasi kepada pembinaan dan pembentukan akhlak yaitu al-akhlaq al-karimah. Akhlak menjadi karakter Islam karena akhlak masuk kepada semua eksistensi Islam dan dalam semua ajarannya, sampai kepada akidah, ibadah, dan muamalah, serta termasuk ke dalam ekonomi dan politik. Dalam kehidupan sehari-hari seseorang sering mendengar cerita tentang peristiwa di dalam lingkungan tempat tinggal. Ada beberapa masyarakat yang mengambil pesan dalam cerita rakyat hanya secara praktis. Jika ditinjau lebih mendalam, banyak pesan dalam cerita rakyat yang dapat diambil, baik dalam pembelajaran secara keseluruhan ataupun ditinjau dari pembelajaran Islam yakni berupa akhlak.

Tujuan penelitian ini adalah mengidentifikasi nilai akhlak pada legenda Malin Kundang dalam perspektif Islam. Penerapan nilai nilai akhlak pada legenda Malin Kundang dalam kehidupan sehari hari. Masalah dalam penelitian ini adalah bagaimana keterkaitan antara nilai akhlak dalam cerita dengan agama Islam.

Penelitian yang mengusung cerita Malin Kundang ini akan dijadikan sebuah buku yang dapat dinikmati oleh semua kalangan, tidak hanya kalangan perguruan tinggi melainkan dapat dinikmati juga oleh pihak sekolah ataupun masyarakat umum. Hal ini sesuai dengan isi yang disampaikan di dalam buku bahwa pendidikan akhlak sangat penting diajarkan dan dipraktikkan pada masyarakat terutama pada anak-anak, baik yang sedang mengenyam pendidikan di sekolah ataupun di luar sekolah.

\section{METODE PENELITIAN}

Penelitian ini merupakan penelitian kualitatif deskriptif yaitu penelitian yang menggambarkan suatu peristiwa atau kejadian yang terjadi pada saat sekarang. Penelitian ini menggunakan metode penelitian fenomenologi karena fenomena yang terjadi pada saat sekarang yaitu jarangnya para orangtua membacakan cerita untuk anak-anaknya. Mereka terlalu sibuk dengan pekerjaannya sendiri atau menurut sebagian besar orangtua, cerita sudah tergantikan dengan adanya media-media yang canggih dan lebih menarik yaitu CD, Play Station, Laptop, dll.

Pawito dalam (Rustiana, 2016) berpendapat bahwa kata gejala (phenomenon yang bentuk jamaknya adalah phenomena) merupakan asal istilah fenomenologi dibentuk dan dapat diartikan sebagai suatu tampilan dari objek, kejadian, atau kondisi-kondisi menurut persepsi. Sebagai suatu gerakan dalam berfikir, fenomenologi dapat diartikan sebagai upaya studi tentang pengetahuan yang timbul karena rasa kesadaran ingin mengetahui. Objek pengetahuan berupa gejala atau 
kejadian-kejadian dipahami melalui pengalaman secara sadar. Fenomenologi menganggap pengalaman yang aktual sebagai data tentang realitas yang dipelajari.

\section{HASIL PENELITIAN DAN PEMBAHASAN}

Temuan dalam penelitian ini adalah nilai akhlak dalam legenda Malin Kundang yang dilihat berdasarkan tokoh yang terdapat dalam cerita. Tokoh dalam cerita ada empat yaitu, Malin Kundang, Mande Rubiyah (Ibu Malin Kundang), Istri Malin Kundang, dan Nahkoda Kapal. Adapun nilai akhlak dalam legenda Malin Kundang penulis rincikan pada tabel berikut.

\section{A. Hasil Penelitian}

\section{Nilai Akhlak Malin Kundang}

Nilai akhlak Malin Kundang terdiri atas tujuh nilai akhlak berdasarkan kutipan yang diambil dari cerita legenda Malin Kundang. Nilai akhlak dan kutipan terdapat pada tabel berikut.

Tabel 4.1 Nilai Akhlak Malin Kundang

\begin{tabular}{|c|c|c|c|}
\hline No & NAMA TOKOH & BUKTI KUTIPAN & $\begin{array}{c}\text { NILAI } \\
\text { AKHLAK }\end{array}$ \\
\hline 1 & & $\begin{array}{l}\text { Kutipan } 1 \\
\text { "Ibu tenanglah, tidak akan terjadi apa-apa } \\
\text { denganku," }\end{array}$ & $\begin{array}{l}\text { Sopan } \\
\text { Santun }\end{array}$ \\
\hline 2 & & $\begin{array}{l}\text { Kutipan } 2 \\
\text { "Ini kesempatan Bu, karena belum tentu } \\
\text { setahun sekali ada kapal besar merapat di } \\
\text { pantai ini. }\end{array}$ & Jujur \\
\hline 3 & & $\begin{array}{l}\text { Kutipan } 3 \\
\text { "Aku ingin mengubah nasib kita Bu, } \\
\text { izinkalah. }\end{array}$ & $\begin{array}{l}\text { Rendah } \\
\text { Hati }\end{array}$ \\
\hline 4 & Malin Kundang & $\begin{array}{l}\text { Kutipan } 4 \\
\text { Malin Kundang medorong ibunya hingga } \\
\text { tergolong ke pasir. "Wanita gila, aku bukan } \\
\text { anakmu," }\end{array}$ & $\begin{array}{l}\text { Angkuh dan } \\
\text { Sombong }\end{array}$ \\
\hline 5 & & $\begin{array}{l}\text { Kutipan } \mathbf{5} \\
\text { Malin menendang Mande Rubyah dan } \\
\text { berkata " Hai wanita gila, Ibuku tidak seperti } \\
\text { engkau, melarat dan kotor. }\end{array}$ & $\begin{array}{l}\text { Durhaka } \\
\text { dan } \\
\text { Takabur }\end{array}$ \\
\hline 6 & & $\begin{array}{l}\text { Kutipan } 6 \\
\text { Tiba tiba, datanglah badai besar } \\
\text { menghantam kapal Malin Kundang, lalu } \\
\text { sembaran petir menggelegar. Kapal hancur } \\
\text { berkeping keping. }\end{array}$ & $\begin{array}{l}\text { Durhaka } \\
\text { dan } \\
\text { Takabur }\end{array}$ \\
\hline 7 & & $\begin{array}{l}\text { Kutipan } 7 \\
\text { Esok harinya, terlihat kepingan kapal yang } \\
\text { telah menjadi batu menyerupai tubuh } \\
\text { manusia bertekuk lutut. Itulah kapal Malin } \\
\text { Kundang }\end{array}$ & Durhaka \\
\hline & & ANALISIS NILAI AKHLAK PADA LEGENDA MALIN KUNDANG DALAM PERSPE & KTIF ISLAM \\
\hline
\end{tabular}


Berdasarkan tabel di atas dapat diuraikan bahwa Malin Kundang merupakan anak yang sopan santun, jujur, dan rendah hati. Malin Kundang sangat sayang dan patuh ibunya. Rasa sayang dan cinta pada Ibunya, Malin berusaha untuk memperbaiki ekonomi keluarganya. Inilah yang membuat Malin Kundang pergi merantau. Namun nilai akhlak sopan santun, jujur, dan rendah hati Malin Kundnag tidak mampu menopang dirinya setelah menjadi orang sukses. Akhlak Malin berubah menjadi angkuh, sombong, durhaka, dan takabur. Hal ini merupakan nilai akhlak yang tidak patut ditiru.

\section{Nilai Akhlak Mande Rubyah (Ibu Malin Kundang)}

Nilai akhlak Mande Rubyah (Ibu Malin Kundang) terdiri dari delapan nilai akhlak berdasarkan kutipan yang yang diambil dari cerita Legenda Malin Kundang. Nilai akhlak dan kutipan terdapat pada tabel berikut.

Tabel 4.2 Nilai Akhlak Mande Rubyah

\begin{tabular}{|c|c|c|c|}
\hline NO & NAMA TOKОН & BUKTI KUTIPAN & $\begin{array}{c}\text { NILAI } \\
\text { AKHLAK }\end{array}$ \\
\hline 1. & & $\begin{array}{l}\text { Kutipan } 1 \\
\text { "Jangan Malin, ibu takut terjadi sesuatu } \\
\text { denganmu di tanah rantau sana. } \\
\text { Menetaplah saja di sini, temani ibu," ucap } \\
\text { ibunya sedih setelah mendengar keinginan } \\
\text { Malin yang ingin merantau. }\end{array}$ & Penyayang \\
\hline 2. & & $\begin{array}{l}\text { Kutipan } \mathbf{2} \\
\text { "Baiklah, ibu izinkan. Cepatlah kembali, ibu } \\
\text { akan selalu menunggumu Nak," kata } \\
\text { ibunya sambil menangis. }\end{array}$ & $\begin{array}{l}\text { Perhatian dan } \\
\text { baik }\end{array}$ \\
\hline 3. & Mande & $\begin{array}{l}\text { Kutipan } 3 \\
\text { "Untuk bekalmu di perjalanan," katanya } \\
\text { sambil menyerahkannya pada Malin. }\end{array}$ & Perhatian \\
\hline 4. & $\begin{array}{l}\text { Rubayah } \\
\text { (Ibu Malin } \\
\text { Kundang) }\end{array}$ & $\begin{array}{l}\text { Kutipan } 4 \\
\text { "Sudah sampai manakah kamu berlayar } \\
\text { Nak?" tanyanya dalam hati sambil terus } \\
\text { memandang laut. la selalu mendo'akan } \\
\text { anaknya agar selalu selamat dan cepat } \\
\text { kembali. }\end{array}$ & $\begin{array}{l}\text { Cemas/ } \\
\text { Khawatir }\end{array}$ \\
\hline 5. & & $\begin{array}{l}\text { Kutipan } 5 \\
\text { "Apakah kalian melihat anakku, Malin? } \\
\text { Apakah dia baik-baik saja? Kapan ia } \\
\text { pulang?" tanyanya. }\end{array}$ & $\begin{array}{l}\text { Cemas/ } \\
\text { Khawatir }\end{array}$ \\
\hline 6. & & $\begin{array}{l}\text { Kutipan } 6 \\
\text { "Malin, anakku. Kau benar anakku kan?" } \\
\text { katanya menahan isak tangis karena } \\
\text { gembira, "Mengapa begitu lamanya kau } \\
\text { tidak memberi kabar?" }\end{array}$ & Pemikir \\
\hline
\end{tabular}




\begin{tabular}{llc} 
NO NAMA TOKOH & \multicolumn{1}{c}{ BUKTI KUTIPAN } & \multicolumn{1}{c}{ NILAI } \\
AKHLAK
\end{tabular}

Mande Rubyah sebagai Ibu Malin Kundang merupakan sosok ibu yang penyayang, perhatian, baik, suka cemas, khawatir, pemikir, dan sedih. Berdasarkan kutipan cerita, terlihat Mande Rubyah berusaha memenuhi kebutuhan Malin dengan rajin bekerja. Saat Malin sakit pun Mande Rubyah bersusah payah dengan sekuat tenaga menjaga dan merawat anak semata wayangnya. Namun ada akhlak Mande Rubyah yang kurang baik yaitu pendendam.

\section{Nilai Akhlak Istri Malin Kundang}

Nilai akhlak Istri Malin Kundang terdiri atas dua nilai akhlak berdasarkan kutipan yang diambil dari cerita Legenda Malin Kundang. Nilai akhlak dan kutipan terdapat pada tabel berikut.

Tabel 4.3 Nilai Akhlak Istri Malin Kundang

\begin{tabular}{lcll} 
NO & NAMA TOKOH & \multicolumn{1}{c}{ BUKTI KUTIPAN } & \multicolumn{1}{c}{ NILAI } \\
AKHLAK
\end{tabular}

Istri Malin Kundang merupakan sosok istri yang angkuh dan pemarah. Istri Malin tidak menerima mertuanya seorang yang tua renta dan miskin. Dengan angkuh dan marah dia menolak untuk menghampiri Mande Rubyah. 


\section{Nilai Akhlak Nahkoda Kapal}

Nilai akhlak nahkoda kapal terdiri atas satu nilai akhlak berdasarkan kutipan yang diambil dari cerita legenda Malin Kundang. Nilai akhlak dan kutipan terdapat pada tabel berikut.

Tabel 4.4 Nilai Akhlak Nahkoda Kapal

\begin{tabular}{|c|c|l|c|}
\hline NO & NAMA TOKOH & \multicolumn{1}{|c|}{ BUKTI KUTIPAN } & $\begin{array}{c}\text { NILAI } \\
\text { AKHLAK }\end{array}$ \\
\hline 1 & Nakoda Kapal & $\begin{array}{l}\text { Kutipan 1 } \\
\text { "Mande, tahukah kau, anakmu kini } \\
\text { telah menikah dengan gadis cantik, } \\
\text { putri seorang bangsawan yang sangat } \\
\text { kaya raya," ucapnya saat itu. }\end{array}$ & Baik Hati \\
\hline
\end{tabular}

Berdasarkan tabel di atas terlihat bahwa Nahkoda Kapal merupakan orang yang baik hati. Dengan jelas dia menyampaikan pada Mande Rubyah bahwa anak Mande Rubyah sudah menikah dan menjadi orang kaya. Informasi Nahkoda Kapal membuat Mande Rubyah bersenang hati dan berharap bisa bertemu anaknya.

\section{B. Pembahasan}

\section{Nilai Akhlak Malin Kundang dalam Perspektif Islam}

Berdasarkan tabel di atas dapat dijelaskan bahwa nilai akhlak dalam perspektif islam pada tokoh Malin Kundang adalah akhlak karimah dan akhlak mazmumah. Akhlak karimah meliputi sopan santun, jujur, dan rendah hati. Akhlak tersebut dalam Al-Quran ditegaskan pada QS. Al Ahqaf ayat 15, Al Maidah ayat 8, Al A'Raf ayat 55. Hal ini menunjukkan bahwa seorang anak harus berbuat baik dan bersikap sopan santun pada orang tua. Orang tua tidak hanya melahirkan dan mendidik anaknya tetapi juga pintu surga bagi anaknya. Pertolongan Allah akan datang kepada seorang anak yang berbakti pada orang tuanya.

Berdasarkan perspektif Islam, nilai akhlak pada Malin Kundang juga termasuk kategori akhlak mazmumah yaitu sombong dan angkuh. Dalam AlQuran surat Lukman ayat 18 ditegaskan bahwa manusia jangan bersikap sombong dan membanggakan diri terhadap apa yang dia punya. Relevan dengan sikap Malin Kundang yang sangat sombong dan angkuh dengan kesuksesan yang telah diraih dengan harta yang berlimpah. Hal ini menunjukkan bahwa manusia meupakan ciptaan Allah yang kedudukannnya sama di mata Allah. Adapun yang membedakannya adalah ketakwaannya. Jadi, tidak pantas manusia untuk brsikap sombong terhadap apa yang dilebihkan Allah kepadanya karena semua yang diperoleh atas kehendak Allah. 


\section{Nilai Akhlak Mande Rubyah dalam Perspektif Islam}

Berdasarkan tabel di atas dapat dijelaskan bahwa nilai akhlak dalam perspektif Islam pada tokoh Mande Rubyah adalah akhlak karimah dan akhlak mazmumah. Akhlak karimah meliputi penyayang, perhatian dan baik, perhatian, cemas atau khawatir, pemikir, suka sedih. Akhlak tersebut dalam Al-Quran ditegaskan pada QS. Maryam ayat 96, Qashash ayat 77, Ahzab ayat 19, Al Baqarah ayat 165, dan An Anbiya 35.

Hal ini menunjukkan bahwa seorang ibu selalu menyayangi dan memperhatikan anaknya meskipun anak tidak berbuat demikian pada ibunya. Ibu yang telah mengandung dan melahirkan selalu baik pada anaknya dan perhatiannya melebihi apapun. Ibu merasa cemas apabila terjadi sesuatu pada anaknya. Hal ini terlihat dari hati ibunya Malin yang sering cemas atau khawatir terhadap anaknya. Mande Rubyah juga sering merasa sedih ketika menunggu kabar anaknya yang tak kunjung menemuinya. Kasih sayang dan perhatian seorang ibu kepada anaknya tidak ada yang mampu menyamainya.

Berdasarkan perspektif Islam, nilai akhlak pada Mande Rubyah juga termasuk kategori akhlak mazmumah yaitu pendendam. Dalam QS As Syura ayat 20 ditegaskan bahwa balasan suatu kejahatan adalah kejahatan yang serupa, maka barang siapa memaafkan dan berbuat baik maka pahalanya atas (tanggungan) Allah. Sesungguhnya Allah tidak menyukai orang-orang yang zalim. Relevan dengan sikap Mande Rubyah yang pendendam seperti kutipan berikut.

"Ya, Tuhan, kalau memang dia bukan anakku, aku maafkan perbuatannya tadi. Tapi kalau memang dia benar anakku yang bernama Malin Kundang, aku mohon keadilanmu, Ya Tuhan!" ucapnya pilu sambil menangis.

Kutipan tersebut menunjukkan betapa ibunya merasa dendam dan meminta keadilan pada Allah atas perbuatan anaknya yang durhaka dan tidak mengakui Mande Rubyah sebagai ibu kandungnya. Anaknyanyang sudah sukses tidak mau menganggap ibunya sebagai ibu kandung dan hal itu membuat Mande Rubyah berbuat demikian.

\section{Nilai Akhlak Istri Malin Kundang dalam Perspektif Islam}

Berdasarkan tabel di atas dapat dijelaskan bahwa nilai akhlak dalam perspektif Islam pada tokoh Istri Malin Kundang adalah akhlak mazmumah. Akhlak mazmumah meliputi angkuh dan pemarah. Akhlak tersebut dalam AlQuran ditegaskan pada QS. Lukman ayat 18 dan Al Imran ayat 134. Dalam QS Lukman ayat 18: 
"Dan janganlah kamu memalingkan mukamu dari manusia (karena sombong) dan janganlah kamu berjalan di muka bumi dengan angkuh. Sesungguhnya Allah tidak menyukai orang-orang yang sombong lagi membanggakan diri."

Kutipan terjemahan tersebut menjelaskan bahwa manusia tidak boleh sombong dan angkuh, namun Istri Malin Kundang memiliki akhlak yang sebaliknya. Dia angkuh dan merasa bahwa dirinya mampu dan kaya. Selain itu Istri Malin Kundang juga memiliki akhlak pemarah. Hal itu terlihat dari kutipan berikut.

"Bukankah dulu kau katakan bahwa ibumu adalah seorang bangsawan yang sederajat denganku?"

Kutipan cerita tersebut menunjukkan bahwa Istri Malin Kundang marah dan kecewa atas kenyataan bahwa ibu Malin Kundang adalah orang biasa, bukan bangsawan seperti yang diceritakan Malin Kundang. Dalam perspektif Islam, hal ini termasuk dalam QS. Al Imran ayat 134 yang artinya yaitu orangorang yang menafkahkan (hartanya), baik di waktu lapang maupun sempit, dan orang-orang yang menahan amarahnya dan memaafkan (kesalahan) orang. Allah menyukai orang-orang yang berbuat kebajikan.

\section{Nilai Akhlak Nahkoda Kapal dalam Perspektif Islam}

Berdasarkan tabel di atas dapat dijelaskan bahwa nilai akhlak dalam perspektif Islam pada tokoh Nahkoda kapal adalah akhlak karimah. Akhlak karimah meliputi baik hati. Akhlak tersebut dalam Al-Quran ditegaskan pada Al Baqarah ayat 195. Hal ini menunjukkan bahwa seorang insan harus berbuat baik kepada orang lain. Seseorang yang berbuat baik untuk orang lain akan dibalas kebaikan juga. Orang jahat akan mendapat balasan atas perbuatan jahatnya, seperti terjemahan dalam QS. Al Baqarah ayat 195 yang berbunyi:

"Dan belanjakanlah (harta bendamu) di jalan Allah, dan janganlah kamu menjatuhkan dirimu sendiri ke dalam kebinasaan, dan berbuat baiklah, karena sesungguhnya Allah menyukai orangorang yang berbuat baik."

Dalam Al-Quran surat Al Baqarah ayat 195 ditegaskan bahwa manusia jangan menjatuhkan diri sendiri ke dalam kebinasaan, dan Allah menganjurkan agar berbuat baik, karena Allah menyukai orang-orang yang berbuat baik. Penjelasan ayat tersebut relevan dengan sikap Nahkoda kapal. Dia memiliki sifat yang baik hati kepada semua orang. 


\section{SIMPULAN}

Berdasarkan hasil analisis data, ada beberapa nilai akhlak yang terdapat pada legenda Malin Kundang. Nilai akhlak pada Malin Kundang, Mande Rubyah, Istri Malin Kundang, dan Nahkoda kapal. Malin Kundang memiliki akhlak sopan santun, jujur, dan rendah hati, sombong, dan angkuh. Mande Rubyah memiliki akhlak penyayang, perhatian dan baik, perhatian, cemas atau khawatir, pemikir, suka sedih, dan pendemdam. Istri Malin Kundang memiliki akhlak angkuh dan pemarah. Nahkoda kapal memiliki akhlak baik hati.

Nilai akhlak dalam perspektif islam meliputi nilai akhlak karimah yaitu nilai terpuji dan nilai akhlak mazmumah yaitu nilai tercela. Malin Kundang memiliki akhlak karimah meliputi sopan santun, jujur, dan rendah hati dan akhlak mazmumah sombong dan angkuh. Mande Rubyah memiliki akhlak karimah meliputi penyayang, perhatian dan baik, perhatian, cemas atau khawatir, pemikir, suka sedih, dan akhlak mazmumah pendemdam. Istri Malin Kundang memiliki akhlak mazmumah meliputi angkuh dan pemarah. Nahkoda kapal memiliki akhlak karimah meliputi baik hati.

\section{SARAN}

Berdasarkan hasil penelitian yang telah disimpulkan di atas, peneliti dapat menunjukkan adanya nilai akhlak yang terkandung dalam legenda Malin Kundang. Saran-saran hasil penelitian ini adalah sebagai berikut.

1. Bagi Anak

Penelitian ini dapat digunakan sebagai salah satu metode sosialisasi karakter kepada anak sejak dini dengan menggali kekuatannya melalui kegiatan yang mengarahkan anak untuk melakukan perilaku berkarakter dan menanamkan nilai positif.

2. Bagi Ibu

Penelitian ini bisa digunakan oleh seorang ibu sebagai salah satu cara menyampaikan akhlak baik dan buruk kepada anaknya atau anak didiknya.

3. Bagi Masyarakat

Penelitian ini dapat dimanfaatkan oleh masyarakat untuk memperkenalkan adanya cerita rakyat di suatu daerah terutama cerita Malin Kundang yang nilai-nilainya dapat diambil sebagai pengalaman hidup bermasyarakat.

\section{DAFTAR PUSTAKA}

Faruk. 2014. Metode Penelitian Sastra, Sebuah Penjelajahan Awal. Yogyakarta: Pustaka Pelajar.

Endraswara, Suwardi. 2013. Metodologi Penelitian Sastra. Yogyakarta: Caps.

Khoerotunnisa, Siti. 2016. Nilai nilai Akhlak dala Perspektif Pendidikan Islam (Kajian Tafsir Surat Al-Hujurat Ayat 11-13). 2016. http://erepository.perpus.iainsalatiga.ac.id/1429 
Nasharuddin. 2015. Akhlak (Ciri Manusia Paripurna). Jakarta: PT Raja Grafindo Persada.

Nurgiyantoro, Burhan. 2002. Teori Pengkajian Fiksi. Yogyakarta: Gadjah Mada University Press.

Rafiek, M. 2015. Teori Sastra: Kajian Teori dan Praktik. Bandung: PT. Refika Aditama.

Rizal, Syamsul. 2018. Akhlak Islami Prespektif Ulama Salaf. Vol. 07, No. 1. Jurnal Pendidikan Islam.

Subaiti, Musa Jawad. 1995. Akhlak Keluarga Muhammad SAW. Jakarta: PT Lentera Basritama.

Tafsir, Ahmad. 1994. Ilmu Pendidikan dalam Perspektif Islam. Bandung: Remaja Rosda Karya.

Wahyudin, Wisrawaty. 2016. Kemampuan menentukan isi cerita rakyat kelas X SMA Negeri 1 Raha. Jurnal vol. 1, no. 1. 